
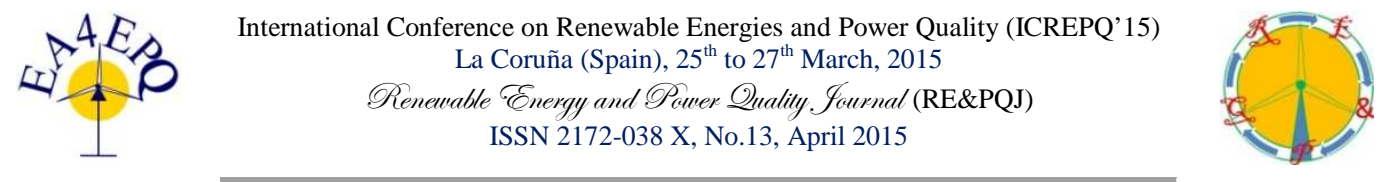

\title{
Vertical Axis Wind Turbines: Current Technologies and Future Trends
}

\author{
J. Damota ${ }^{1}$, I. Lamas ${ }^{2}$, A. Couce ${ }^{1}$, J. Rodríguez ${ }^{1}$ \\ ${ }^{1}$ Marine Innovations Research Group \\ E.U.P. A Coruna University \\ Avda 19 feb, s/n - 15405 Ferrol (Spain) \\ Phone number: +0034 981337400 - 3002, e-mail: javier.blanco.damota@udc.es acouce@udc.es, \\ jdedios@udc.es \\ ${ }^{2}$ Thermal Systems and Heat Transfer Research Group \\ E.P.S. A Coruna University \\ C/ Mendizabal, s/n Esteiro 15403 Ferrol (Spain) \\ Phone number: +0034 981337400 - 3002, e-mail: isabellamas@udc.es
}

\begin{abstract}
This paper, based on the pursuit of scientific articles published and recorded in the last five years (2010-2014) patents on VAWT technology, gives an image of the current situation of the treated technology.

From data extracted we know:

The different models that are working with different geometries, distinguishing between Savonius, Darrieus, hybrid of both $(\mathrm{D}+\mathrm{S})$, models dedicated to Offshore technology and what can be applied generally (D\&S) on both types of VAWT (controllers, electric generators, materials ...).
\end{abstract}

The main countries that research and develop VAWT technology, globally and at European level and the number of dedicated studies and patents each.

Multiple applications that can be given in fields such as building, industrial environment, social areas, civil engineering and other more.

Future trends for VAWT, which can be seen in our environment, both rural and urban, as has already happened with other renewable technologies for electricity production, as HAWT and photovoltaic (PV), becoming part of the mix of renewable energy technology and business network of the future, thereby contributing to the reduction of $\mathrm{CO}_{2}$ production and economic growth.

\section{Keywords}

VAWT, Savonius, Darrieus, green energy

\section{Introduction to VAWT technology.}

A wind turbine converts the kinetic energy in wind into mechanical energy, which will be reflected on its axis. To convert this mechanical energy into electrical energy, the turbine has to be coupled to an electrical generator, becoming a wind turbine.

To perform this task, several types of turbines are used, differentiated into two types by the position of its axis of rotation with respect to the surface on which it is fixed, and can be then Horizontal Axis Wind Turbines (HAWT), the most common turbines, used mostly in wind farms for high-energy production, and Vertical Axis Wind Turbines (VAWT), latter less common and currently are the subject of numerous studies and developments of new models.

Within the VAWT's, there are two types, differentiated by the morphology of their blades.

Savonius type or S turbine, created in 1922, is composed of two circular cross-sections blades, one placed concavely and one convexly towards the wind position and vertically arranged along an axis of rotation with the particular feature that the blades are overlapping in the vicinity of the rotation axis, making the effect of support by exchanging the flow between both blades, thus achieving assistance for the starting factor that receive both blades to be positive in the wind direction and thereby getting movement. 


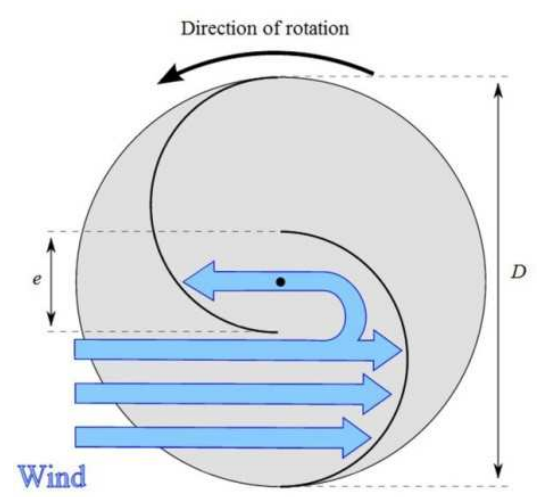

Fig. 1. Conventional Savonius wind turbine. Effect of overlapping use of blades.

The second type of VAWT is the Darrieus type, which was created in 1931, has the particularity that the blades are aerodynamically shaped, usually NACA style, with different layouts and with a certain distance from the axis of rotation.

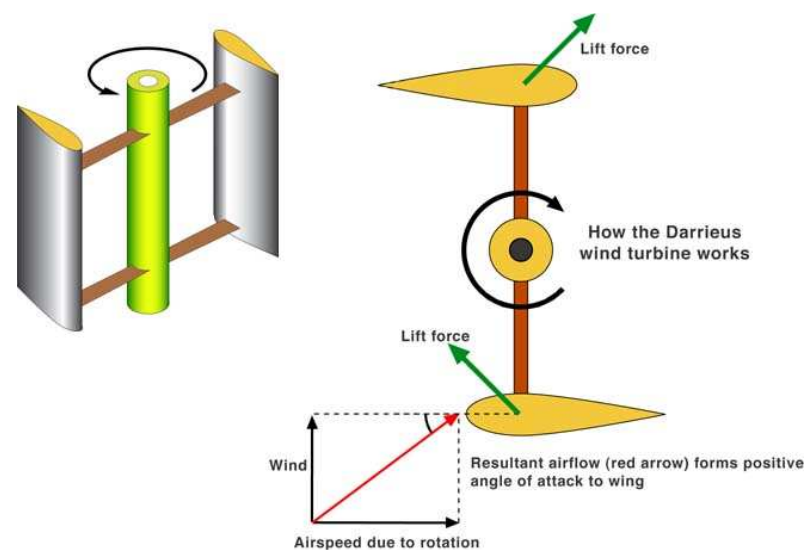

Fig. 2. Explanation of how a Darrieus turbine generates movement.

Among the VAWT, the substantial differences between them are:

The Savonius Wind Turbine, starts at lower velocities than the Darrieus one, in fact, Darrieus Wind Turbines need electric support in order to boot, and its removal rates are $4-5 \mathrm{~m} / \mathrm{s}$ [1], while the Savonius wind starts at 1 $\mathrm{m} / \mathrm{s}$ or even lower [2].

In order to exploit these starting properties from each of the technologies, there are hybrid turbines, which consist of two turbines; a Savonius type for starting at low speed, and therefore saving power supply necessary for the second turbine starter, one Darrieus type, which obtains a power coefficient (CP) higher than the Savonius type at high speed winds.

The CP is one of the other differences, being higher those obtained in studies for Darrieus Wind Turbine, and can reach values close to 0.4 , compared to 0.3 which can reach a Savonius Wind Turbine [3].

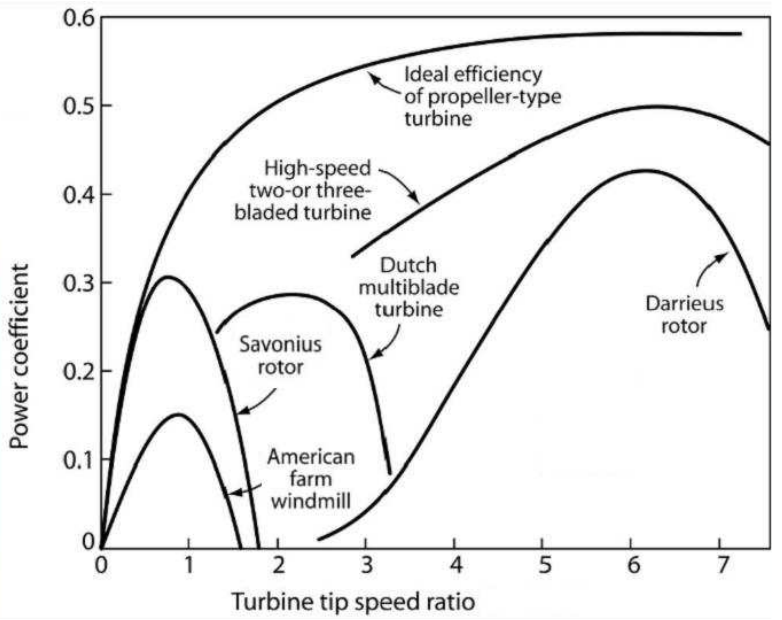

Fig. 3. Power coefficients for different wind power generators.

As regards the differences between HAWT and VAWT wind turbines with capacities below $10 \mathrm{~kW}$, these include:

- They do not need to be at great height to produce energy, since they boot at low wind speeds.

- They generate electric power at high and very high wind speeds, at which the horizontal axis generators would not work for possible damage.

- They are easy to install and a very low maintenance and easier than the horizontal axis ones since the generator is located at the lower part of the structure, making it easier to access it when you perform any maintenance.

- They produce a low or zero noise pollution, which means that it can easily be adapted to urban noise pollution regulations.

- They could be assembled several wind turbines on a small surface since they do not need to keep large distances between them because of the lack of braking air production.

- They provide us wide ranges of benefit from recoverable wind energy in buildings, facades and in any urban area where low altitude winds are remarkable and the construction of a conventional wind farm is unfeasible.

- They do not imply a visual impact, as they suit to images that can be viewed at any building or urban area.

In Spain the use of these technologies for small productions isn't exploited in practice, it does not even have a specific regulatory framework, while in some countries around us (Portugal, Italy and France), have specific regulations for small wind energy. In more advanced nations, such as the UK, they have set a target for 2050, this is that the country's electricity production will be $30-40 \%$ from distributed generation in buildings through the program "Low Carbon Buildings". UK currently has about 100,000 micro-generation facilities and producers even receive tax incentives. [4]

It should be noted that the European Union, through the directive 2009/28/EC of European Parliament, set that a minimum of $20 \%$ of the energy consumed should be 
from renewable energy in 2020, and Spain as a member state must comply legislation and this technology could help to meet that goal.

\section{Papers.}

For the search of information it has been used the website "Web of Science" which is a technological web browser that collects references for the core scientific publications to which the University of A Coruña is subscribed, thus allowing access to the search on its university campuses.

The articles published between 2010-2014 were searched to get a global idea of the evolution of the study in the past five years in the field of VAWT, handling to a total of 358 different articles published, as can be inferred from the total amount of each of the articles provided in the past years which is shown in the following graph:

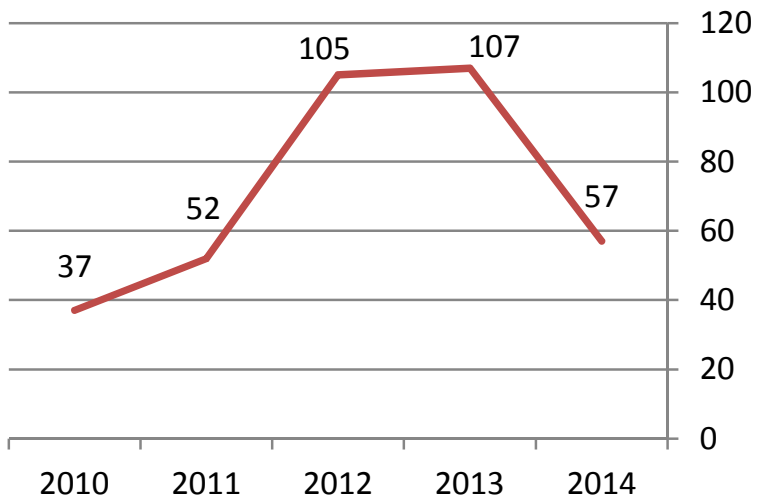

Fig. 4. Number of scientific articles published per year.

If the present trend continues, we can predict that in 2015, publications will drop to 2010 values, reaching values close to 40 publications.

From this search it is worth highlighting the five countries with the highest number of articles dedicated to VAWT technology during the past five years, have been those which can be seen in this graph, as well as the amount of articles published by each of them.

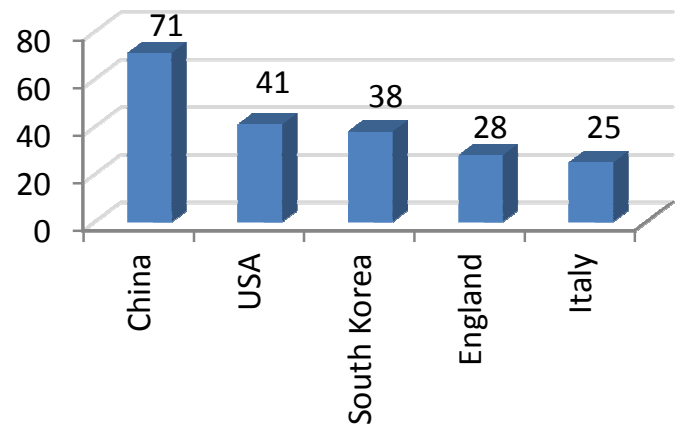

Fig. 5. Top 5 of countries with more publications (2010-2014).

As regards the question about universities, Cranfield University (England) is the entity that has contributed more over the past five years with 11 publications, followed by the University of Padua (Italy) with 9 publications and the California Institute of Technology (USA) with 8 .

Regarding the type of turbine that each of the articles deal with, the following chart shows the percentage of publications dedicated to each of the variants of this technology.

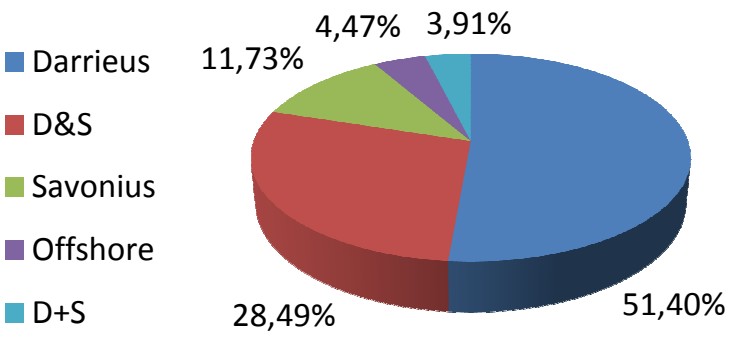

Fig. 6. Dedication of articles.

At European level, the following graph shows that countries such as England and Italy are favouring research on VAWT technology; other European countries such as Sweden, Romania, Netherlands, etc., at a great distance from the first ones, invest less in research of this technology.

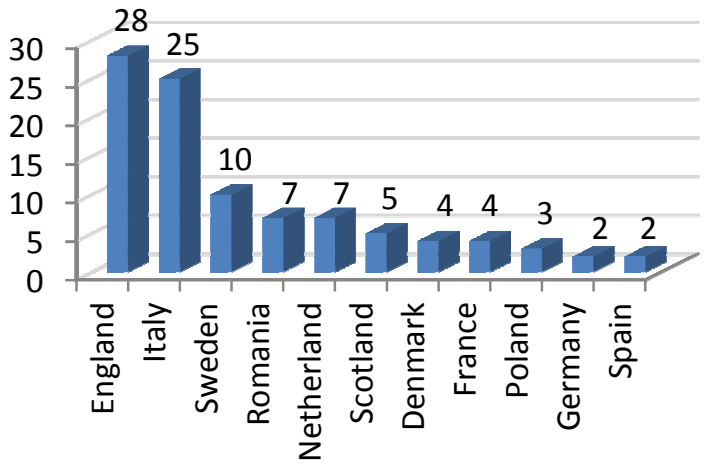

Fig. 7. Publications in Europe (2010 - 2014).

Certainly these countries have observed that the short to medium term, this field is very promising due to the many advantages and applications cited throughout this article.

\section{Patents.}

In order to search information, "Espacenet" has been used. That is, a free access technological web browser that includes more than 90 million worldwide patents.

A search of Patents registered in 2010-2014 has been sought to get an idea of the developments which took place in the past five years in the field of VAWT worldwide, which has made that the amount of data that has been handled out of a total 685 patents, as can be deduced from the sum of the totals for each of the years that shows the following graph: 


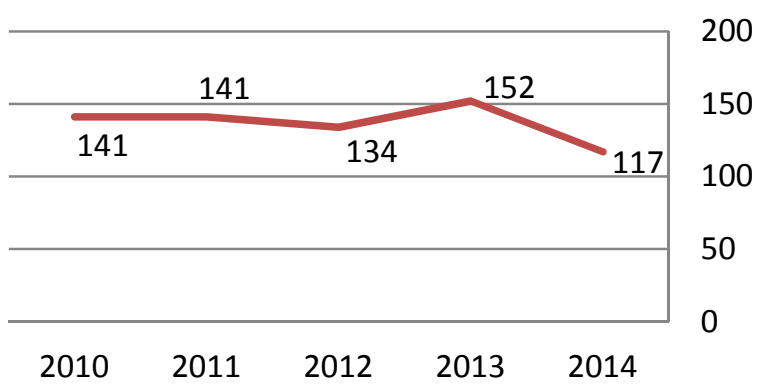

Fig. 8. Number of registered patents per year.

In this graph it can be observed that the evolution of technology patenting to be developed has remained relatively stable from 2010 to 2012, reaching its peak in 2013 and moving immediately to its lowest data in 2014.

From this research can be noted that the five nationalities of inventors who have registered more patents have been those that can be seen in this graph, as well as the amount registered by each of them.

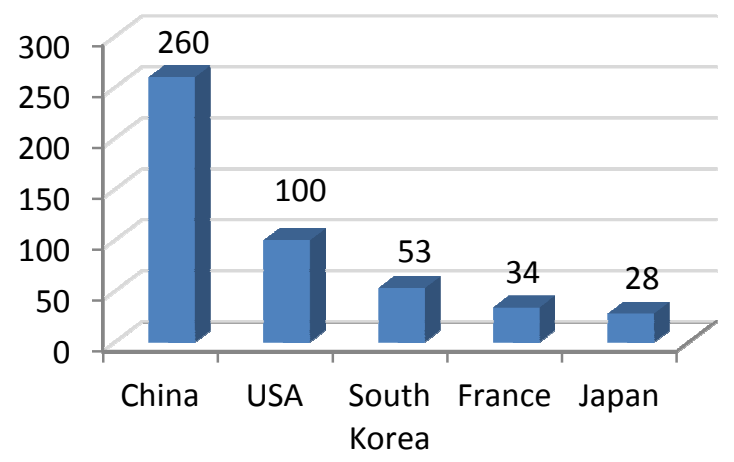

Fig. 9. Top 5 of countries with more patents (2010-2014).

The authority of the Chinese patents over the American ones it is very surprising, China has a 160\% more patents, which let us think that the base as an economic power in China focuses not only in its ability to work harder but also in the diversity of its managerial framework and high dedication in developing new technologies; just the opposite of what countries such as Spain -currently in a period of crisis- do, which has drastically reduced investment in $\mathrm{R} \& \mathrm{D}$.

If we focus on the applicants of such patents, it can be observed that a bit over the 50\% are the inventors themselves, but the remaining percentage is shared by universities, institutions and industry, which will be the operators of the patent rights. These data can be observed in the following graph:

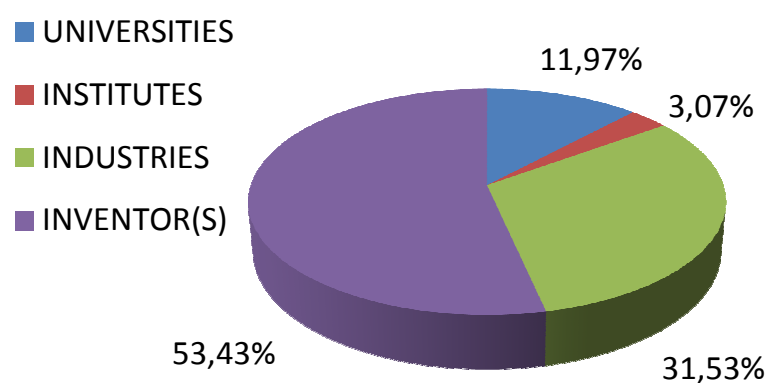

Fig. 10. Applicants \%.

Taking into account the breadth of patent applications, it can be deduced that the majority of patents are registered at regional level, that is within just only one of the countries that had signed the Patent Cooperation Treaty (PCT), while also there are others that cover all countries (WO), the European members (EP) and Eurasian (EA), as seen in the following graph.

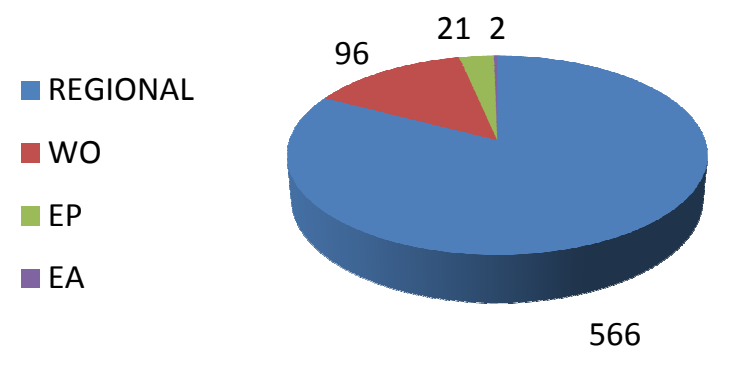

Fig. 11. Patent number registration filing.

And at European level, we can see how countries such as England, Italy and France are committed to the research and development of VAWT, as can be seen in the following graph:

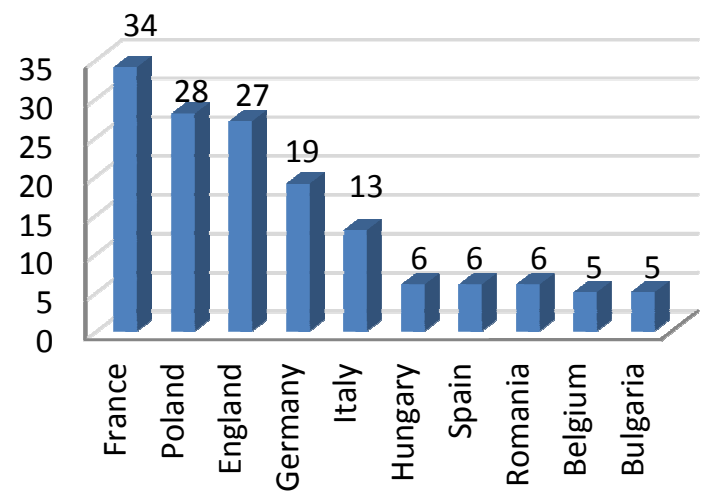

Fig. 12. Patents in European countries.

We can see how countries with a specific regulatory framework for small wind energy (France, England and Italy) recorded the highest number of patents. The protection in its own regulatory framework makes VAWT technology, dedicated largely to the small wind energy $(<10 \mathrm{~kW})$, obtain further development since barriers are reduced when marketing products. 


\section{Applications for VAWT technology.}

-Industrial building.

-Holiday resorts.

-Lighting.

-Fish farms.

-Agricultural and livestock farms.

-Water pumping.

-Irrigation.

-Sports facilities.

-Yacht clubs.

-Golf links.

-Yachts and ships.

-Shopping Centers.

-Residential buildings.

-Total or partial supply of housing.

-Residents' community: Common Areas.

-Public Facilities, Town Planning and Environment.

-Highways, Roads, pedestrian zones and bicycle lanes.

-Squares, parks and leisure areas.

-Civic buildings.

-Treatment Plants.

\section{Future trends.}

Although predicting the future based on data is not always fully conclusive, we can deduce that:

The VAWT technology is sliding into the use in small generating installations, especially in urban environments that currently have winds that are not exploited. There are studies about the omnidirectional-guide-vane which make power, speed and torque increase markedly in these sorts of environments [5].

Employing Wind VAWT in / PV hybrid power generation system can be the solution at many locations since the cost of this system is considered to be lower than the use of both individual technologies [6].

About the studies devoted to the types of optimal generators for producing electricity from wind energy in urban environments it can be drawn that the desired features are:

- Low cogging torque.

-Very high electrical and mechanical efficiency (including the operation of main charge).

- Compact size and high specific torque / power.

- Lower noise and vibration.

- Cheap and easy to manufacture and install.

These features are collected in a prototype of the University of Bristol, which may be the type of generator to be used in the future, a permanent magnet generator (PMG), axial flow and direct drive of $50 \mathrm{~kW}$, with peak power $48 \mathrm{~kW}$ at $500 \mathrm{rpm}$ and have achieved an efficiency of $94 \%$. [7]

The possibility that this type of design is scalable, together with its low maintenance and compact size, opens up to the use of many powers and sizes in wind turbines and can be used in all kinds of applications.

In the design field of turbine geometry, it seems to the helical arrangement of the blades, as has been verified by simulation using numerical methods, the helical increases the power coefficient in comparison with the straight arrangement of the blades increasing from $33 \%$ to $42 \%$ under the same operating conditions [8].

Within the geometry field, it would tend to the increase in the number of blades, the use of different airfoils, the blade pitch angle range and the use of deflectors.

Due to the high cost and risk involved in the physical realization of a model to be submitted to the testing necessary to meet the various operating parameters as well as how changes in the environment and morphology evidence bearing on this, numerous studies have been devoted, through computer programs and various calculation methodologies, to try to improve the performance and efficiency of VAWT [9], and this will continue until noticeable results are achieved and someone bets by the use of technology.

For high volume productions using the technology HAWT large wind turbines will remain the most common used technology, as yields and production are higher when compared with the VAWT. But the use of VAWT small wind farms is not excluded, as it has been concluded that, contrary to what happens to the HAWT The closer they are between them, the lower power coefficient they get, under certain provisions of proximity, VAWT increases it [11]. This does not exclude the situation of small VAWT wind farms on the roofs of buildings or in high places either urban or rural environments.

It would be a little unconscious placing VAWT rather than HAWT in places where the latter generate more production, even having VAWT that reach $4 \mathrm{MW}$, as the case of Éole, located in Cap Chat, Quebec, Canada and with a height of 110 meters and 96 meters in diameter, is the largest ever VAWT installed [12].

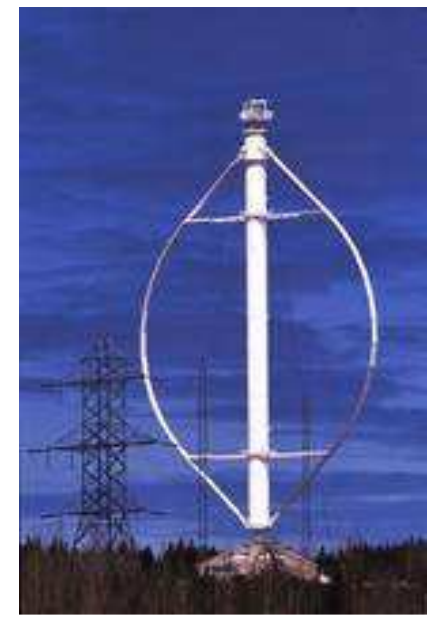

Fig. 13. Éole, the world largest Darrieus wind turbine. 
We must remember that nowadays there are HAWT whose heights are close to 130 meters and close to 100 meters in diameter that can generate up to $10 \mathrm{MW}$ such as the case of offshore wind turbines last generation, such as the SeaTitan of USA company AMSC or ST10 of the Norwegian company Sway, which is compatible for both fixed and floating installations.

The use of VAWT for Offshore situation for great productions is discarded, but it can be said that the use of offshore ones can be designed to supply weather buoys and boats, either individually or through a wind / PV hybrid system.

\section{Conclusions.}

If any conclusion can be drawn is that the VAWT technology undoubtedly will be with us in the future, and can be seen all around us, as has happened with other renewable technologies for electricity production, such as HAWT and PV, thus becoming part of the future renewable energy range and the business network, contributing to the reduction of $\mathrm{CO}_{2}$ production and economic growth.

Even after being a subject to which many studies have been devoted, however we still have a long road ahead and certainly there continue to be many areas to experience.

That is why, after doing this article, the Department of Energy and Marine Propulsion of University of A Coruña, have determined a preliminary geometry for the development of a new model of VAWT, in which is working out, doing various tests using computational methods in order to obtain optimal morphology and even making a preliminary model prototype, thus doing their bit to the development of this technology.

\section{References.}

[1] Herbert J. Sutherland, Dale E. Berg, and Thomas D. Ashwill. "A Retrospective of VAWT Technology". Sandia National Laboratorie. Alburquerque, NewMexico. (2012)

[2] I. Paraschivoiu. "Wind turbine design: with emphasis on Darreius concept". Published by École Polytechnique de Montréal, Canadá. (2002)

[3] Chinchilla, Rigoberto; Guccione, Samuel; and Tillman, Joseph, "Wind Power Technologies: A Need for Research and Development in Improving VAWT's Airfoil Characteristics". Eastern Illinois University. Published by Faculty Research \& Creative Activity. USA (2011).

[4] Editorial Vértice "Desarrollo de proyectos de instalaciones de energía mini-eólica aislada”. Publicaciones Vértice S.L. España (2011).

[5] W.T. Chong, S.C. Poh, A. Fazlian and K.C. Pan "Vertical axis wind turbine with omni direccional guide vane for urban high rise application”Departament of Mechanical Engineering, University of Malaya. Malaysia (2012)

[6] R. Eke, O. Kara and K. Ulgen "Optimization of a Wind/PV Hybrid Power Generation System" Ege University. Turkey (2007)

[7] J.K. Booker, P.H. Mellor, R. Wrobel, D. Drury, "A compact, high efficiency contra-rotating generator suitable for wind turbines in the urban environment," University of Bristol. England (2010)

[8] Tuyen Quang Le, Kwang-Soo Lee, Jin-Soon Park and Jin Hwan Ko. "Flow-driven rotor simulation of vertical axis tidal turbines: A comparison of helical and straight blades". Korea Institute of Ocean Science \& Technology. South Korea (2014).

[9] Sukanta Roy, Ujjwal K. Saha. "Review on the numerical investigation into de design and development of Savonius wind rotors". Indian Institute of Technology Guwahati. India (2013).

[10] European Parliament. Directorate general for internal policies "Mapping Smart Cities in the EU". European Union (2014)

[11] Robert W Whittlesey, Sebastian Liska and John O Dabiri, "Fish schooling as basis for vertical axis wind turbine farm design". California Institute of Technology. USA (2010).

[12] Polv Brondsted and Rogier P.L.Nijessen. "Advances in wind turbine blade design and materials". Woodhead Publishing Limited. UK (2013). 